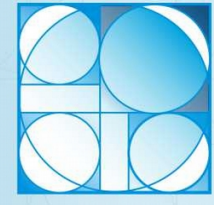

Resumos SBBq - Brasil

Revista de Ensino de Bioquímica

Revista de Enseñanza de Bioquímica

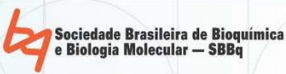

\author{
Symposium - 20 \\ Bachelor of Biochemistry in Brazil \\ Chair: Bayardo B. Torres, IQ-USP
}

\title{
SP.20.3. The bachelor degree in Biochemistry at the University of Maringá: challenges and prospects
}

\author{
Jurandir Fernando Comar \\ Departamento de Bioquímica, University of Maringá-PR, Brazil
}

\begin{abstract}
The bachelor degree in biochemistry at the University of Maringá (UEM) was created in 2010 with the purpose of preparing generalists in biochemistry able to work in various service branches and sectors of the biotechnology industry in addition to academic research. The curricular structure is amply supported by basic exact sciences associated with a wide range of biochemical disciplines from the traditional ones to the technological branches and emphasizes experimental skills. The curriculum additionally includes disciplines that reinforce the close union between biochemistry and molecular biology, as is already widely recognized by scientific societies. Seven years after being launched the course still remains one of only three bachelor degrees in biochemistry in Brazil. Most of the graduates have engaged in stricto sensu post-graduation courses with the purpose of pursuing academic careers. On the other hand, the inclusion of graduates in sectors of the biotechnological industry can be regarded as an important challenge faced by the bachelor's degree in biochemistry. Part of the difficulties can be attributed certainly to the narrow technological base of the Brazilian industry. In the professional sphere, on the other hand, the most serious problem is the absence of a professional career that carries the name of biochemistry. For now, biochemistry in Brazil is spread over several professions. Strategies to modify this scenario and consolidate the career of biochemistry in Brazil should include a greater offer of supervised curricular internship in biotechnological companies and an increased number of courses of bachelor degree in the national higher education system.
\end{abstract}

Keywords: bachelor degree in biochemistry; curricular structure; biochemical carrier. 